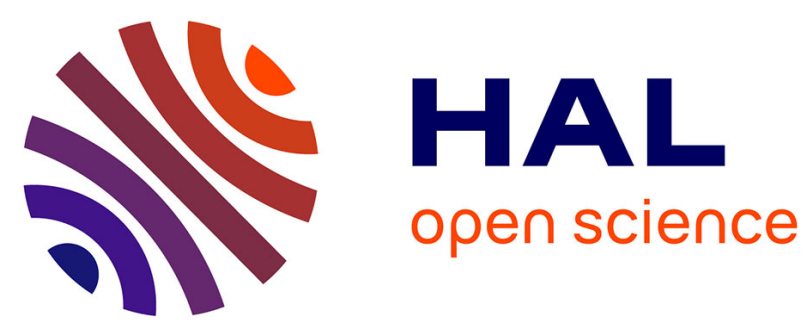

\title{
Selective laser melting of boron carbide particles coated by a cobalt-based metal layer
}

\author{
A. Davydova, A. Domashenkov, A Sova, Igor Movtchan, Philippe Bertrand, \\ Benjamin Desplanques Desplanques, Nathalie Peillon, Sébastien Saunier, \\ Christophe Desrayaud, C. Iacob
}

\section{To cite this version:}

A. Davydova, A. Domashenkov, A Sova, Igor Movtchan, Philippe Bertrand, et al.. Selective laser melting of boron carbide particles coated by a cobalt-based metal layer. Journal of Materials Processing Technology, 2016, 229, pp.361-366. 10.1016/j.jmatprotec.2015.09.033 . emse-01353579

HAL Id: emse-01353579

https://hal-emse.ccsd.cnrs.fr/emse-01353579

Submitted on 13 Sep 2021

HAL is a multi-disciplinary open access archive for the deposit and dissemination of scientific research documents, whether they are published or not. The documents may come from teaching and research institutions in France or abroad, or from public or private research centers.
L'archive ouverte pluridisciplinaire HAL, est destinée au dépôt et à la diffusion de documents scientifiques de niveau recherche, publiés ou non, émanant des établissements d'enseignement et de recherche français ou étrangers, des laboratoires publics ou privés.

\section{(c)(1)}

Distributed under a Creative Commons Attribution| 4.0 International License 


\title{
Selective laser melting of boron carbide particles coated by a cobalt-based metal layer
}

\author{
A. Davydova ${ }^{a}$, A. Domashenkov ${ }^{a}$, A. Sova ${ }^{a}, *$, I. Movtchan $^{a}$, Ph. Bertrand ${ }^{a}$, B. Desplanques ${ }^{b}$ \\ , N. Peillon ${ }^{b}$, S. Saunier ${ }^{b}$, C. Desrayaud ${ }^{b}$, S. Bucher ${ }^{c}$, C. Iacob $^{c}$ \\ a Lyon University, ENISE, LTDS Laboratory, Saint Etienne, France \\ ${ }^{\mathrm{b}}$ Mines Saint-Etienne, LGF Laboratory UMR 5307, Saint Etienne, France \\ ${ }^{c}$ LIFCO Industrie, Saint Etienne, France
}

\begin{abstract}
Selective laser melting (SLM) is an additive manufacturing technology widely applied for direct fab-rication of functional parts from metal powders. In this paper, the feasibility of the fabrication of three-dimensional cermet objects by SLM using 5-35 $\mu \mathrm{m}$ boron carbide particles surrounded by $\sim 2 \mu \mathrm{m}$ cobalt-based layers was explored. Microstructure, composition, porosity, compressive strength and microhardness of the fabricated object were investigated. A highly porous (37\%) homogeneous structure containing grains of boron carbides with 2900-3200 HV hardness embedded in the cobaltbased matrix was obtained. It was also found that new phases were formed during SLM as a result of the interaction of $\mathrm{B}_{4} \mathrm{C}$ with the cobalt-based matrix.
\end{abstract}

\section{Introduction}

Selective laser melting (SLM) of metal powders is an Additive Manufacturing technology with the ability of layer-by-layer building of complex-shape functional parts (Wohlers Report, 2007). The available literature reports successful results of SLM manufacturing of 3D objects and functional parts from steel (Murr et al., 2012), nickel (Jia and Gu, 2014), cobalt (Pupo et al., 2013) and titanium based alloys (Yadroitsev et al., 2014). However, materials with enhanced performance compared to metallic alloys typically applied in SLM are required to withstand harsh operating conditions such as elevated temperature, high abrasive wear, etc. For example, cutting tools materials must have strong characteristics of hardness, wear resistance and compressive strength. Applying different types of ceramic and cermet materials is now emerging as the only solution to achieve this goal. Cutting tools are typically manufactured by sintering ceramic and cermet powders containing tungsten carbide, titanium carbide, titanium carbonitrides or other types of hard phases. SLM of ceramics is a difficult task (Deckers et al., 2014). High temperature gradients during SLM process often lead to parts cracking (Shishkovsky et al., 2007) and high residual stress. Some successful results have been reported on SLM of yttria-stabilized zirconia (YSZ) (Bertrand et al., 2007) and

\footnotetext{
* Corresponding author. Fax: +33 477743497.

E-mail addresses: sova.aleksey@gmail.com, aleksey.sova@enise.fr (A. Sova).
}

alumina-zirconium (Shishkovsky et al., 2007) ceramics. However, the mechanical properties of the obtained materials are significantly lower compared to conventional ceramics. For example, YSZ fabricated by SLM has a very high porosity (44\%) and a poor interlayer adhesion (Bertrand et al., 2007). SLM of cermet powders or mixtures of metal and ceramic powders where the metal phase acts as a binder material seems to be less challenging. In this case, the laser melts the metal phase creating the connection between separated particles of the layer whereas the ceramic particles could remain in solid state (Kumar, 2009) or be partially molten (Gu et al., 2006). However, composition inhomogeneity, phase segregation and high porosity of the resulting structures are common problems of SLM of conventional cermet powders (Kruth et al., 1996) and metal-ceramic powder mixtures (Krakhmalev and Yadroitsev, 2014). It can be caused by the initial inhomogeneity of the material in the powder bed, heat and mass transfer particularities in the molten pool, and melting-solidification process of a multimaterial system.

This paper proposes a method for SLM manufacturing of 3D objects from a cermet cladded powder in which the ceramic core is surrounded by a thin layer of metallic binder. The literature reports successful results of the use of this type of powder in cold spray of nickel-coated alumina (Li et al., 2008) and boron carbide particles (Feng et al., 2012) for coating deposition and, as a tentative experiment, for 3D parts building. Such metal-ceramic powders have never been applied in SLM. 


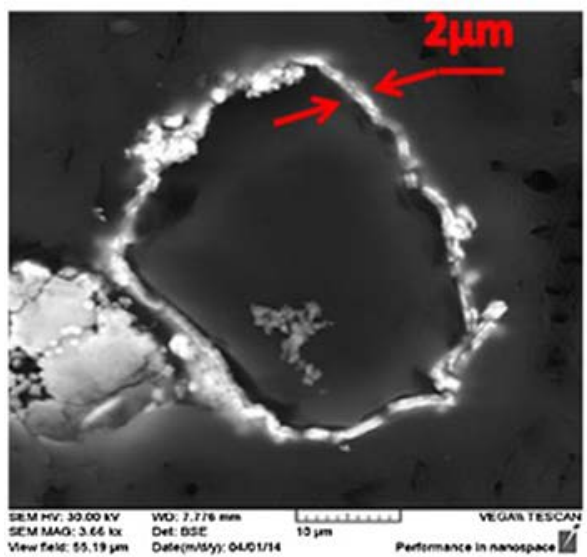

$a$

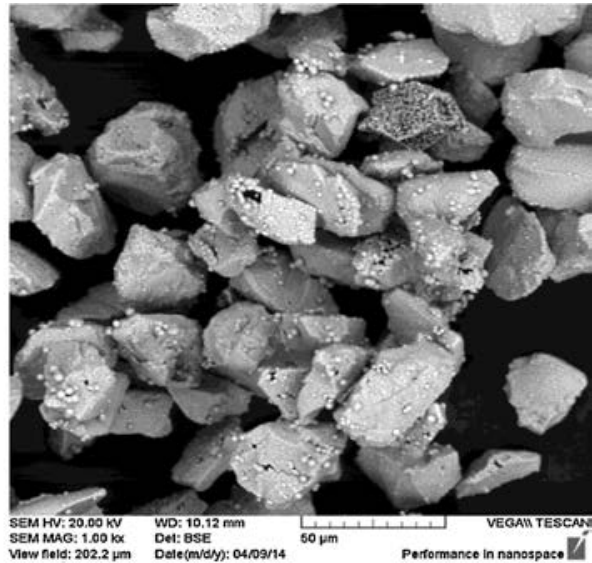

$b$

Fig. 1. SEM images of $\mathrm{B}_{4} \mathrm{C}$ particles coated by a cobalt-based layer used in the experiments: (a) particle cross-section, (b) powder general view.

The main purpose of this study is to explore the feasibility of SLM of a cobalt-cladded boron carbide ceramic powder as a potential solution for additive manufacturing of cutting tools. The choice of boron carbide as a ceramic reinforcing phase was governed by its good mechanical properties, high hardness and high abrasion resistance. Cobalt is actually used as a matrix in cermet materials due to its high corrosion and wear resistance in a wide temperature range. From these considerations, it appears that a cobalt-cladded boron carbide powder may be a good choice to investigate the SLM potential for cutting tools manufacturing.

\section{Experimental procedure}

\subsection{Feedstock material}

Batches of composite metal-coated $\mathrm{B}_{4} \mathrm{C}$ powders were produced using a chemical vapor deposition (CVD) facility for the industrial production of cladded powders (LIFCO Industrie, France). A patented CVD coating process (Bucher and lacob, 2004) was applied using a fluidized bed furnace reactor. The use of a fluidized bed allowed the flow of gaseous reactive species to have a good contact with each particle to be cladded. CVD precursors served to synthesize a cobalt metallic layer reinforced by inclusions of pure boron and $\mathrm{Co}_{3} \mathrm{~B}$ phase deposited onto the surface of fine $\mathrm{B}_{4} \mathrm{C}$ powder.

The particles have a strongly irregular shape; $95 \%$ of the particles have a size lying in the range between 5 and $35 \mu \mathrm{m}$ with an average size of about $13 \mu \mathrm{m}$. SEM analysis of the powder revealed that the average thickness of the cobalt-based coating layer was near $2 \mu \mathrm{m}$ (Fig. 1).
SEM images show that the metallic coating layer is homogenous in thickness but contains some spherical inclusions representing points of nucleation during CVD deposition of cobalt on the ceramic surface of the particles. Also, an amount of particles having visible gaps in the surrounding layer was detected. The percentage of the non-fully covered particles was not measured, but visual observation permitted to estimate their percentage as about 3-5\%. XRD analysis of the particles detected the presence of pure cobalt, pure boron and $\mathrm{CO}_{3} \mathrm{~B}$ phase in the particle coating (Fig. 2).

\subsection{Experimental set-up}

Samples were fabricated using a PM100 (Phenix Systems) SLM machine. The radiation source was a continuous-wave Ytterbium fiber laser YLR-4 × 200-SM (IPG Photonics Corporation) with $1.075 \mu \mathrm{m}$ wavelength and $200 \mathrm{~W}$ maximum laser power. The size of the laser spot on the surface was $70 \mu \mathrm{m}$. The process chamber was filled by argon as a protective gas. Stainless steel plates were used for the tests as a substrate for the powder bed. For a better bonding of the first layer, the substrate was laser cladded with cobalt-reach Stellite 6 powder. The deposited Stellite 6 layer was further on machined and grinded. The resulting coating thickness was $\sim 100 \mu \mathrm{m}$.

\subsection{Characterization of the samples}

The samples were analyzed using an optical microscope Zeiss Axioscope and a SEM Tescan Vega 3 sSB with EDS function.

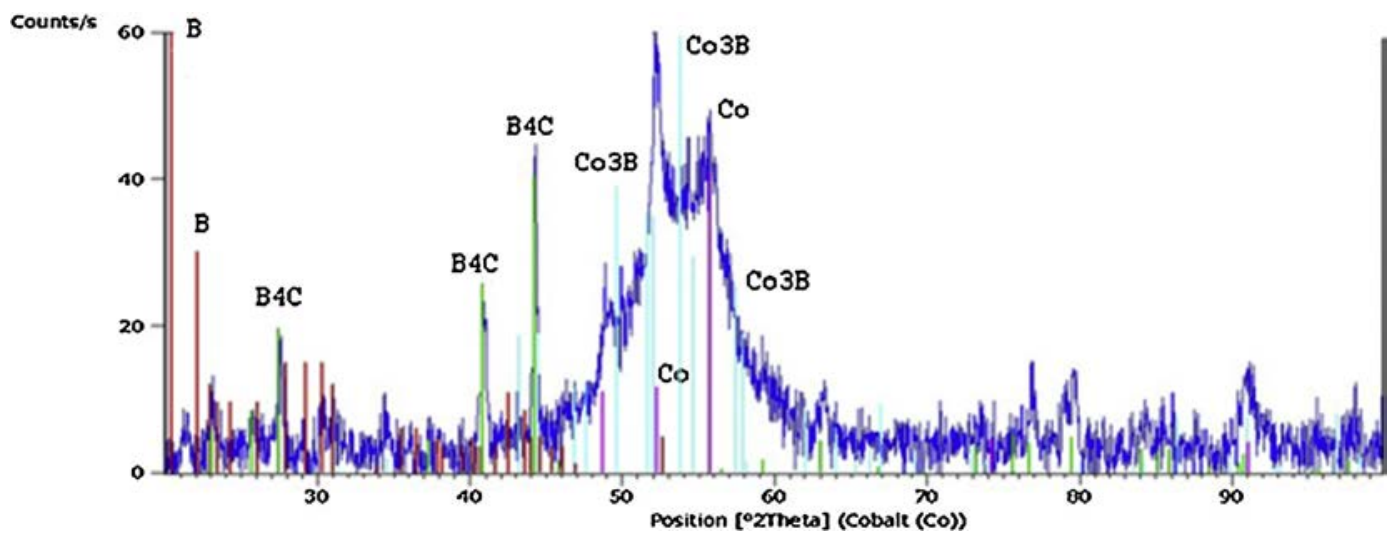

Fig. 2. Results of XRD analysis of $B_{4} C$ powders covered by a cobalt-based layer. 


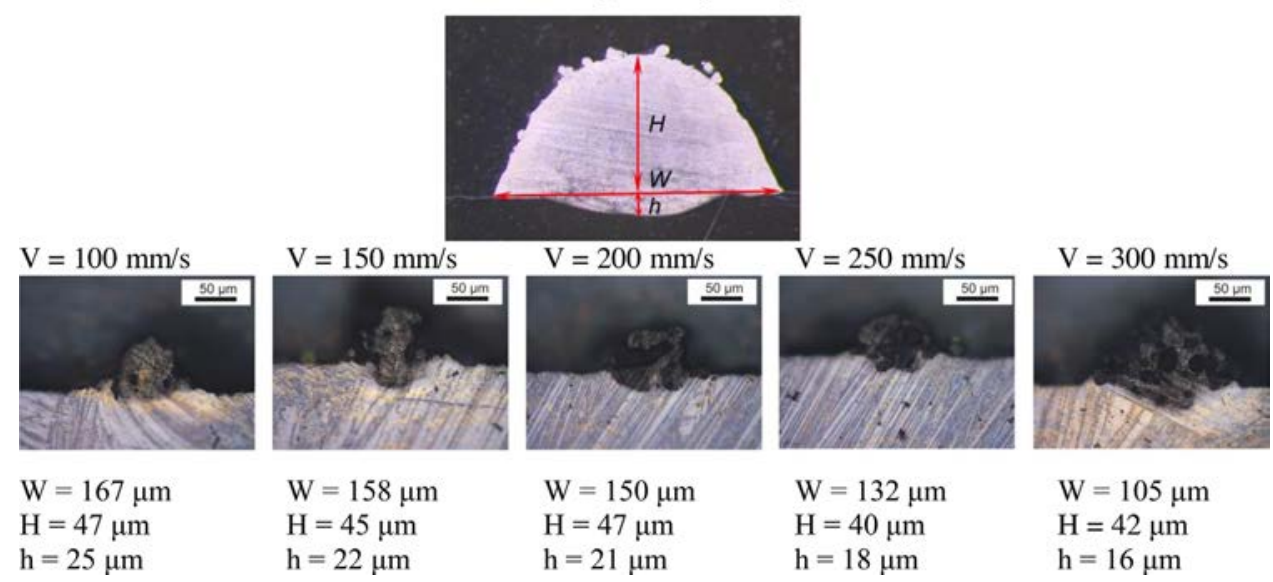

Fig. 3. Geometrical characteristics of the single tracks cross-sections obtained at different laser scanning velocities; laser power $60 \mathrm{~W}$, layer thickness $50 \mu \mathrm{m}$

Microhardness was measured using BUEHLER Omnimet MHT 510 equipment. Powder and samples phase XRD (X-ray diffraction) analysis was performed on Panalytical X'Pert Pro MRD equipment. Density of the 3D samples was measured by Archimedes' method using analytical balances, and compressive strength was measured using a tensile-testing machine.

\section{Results}

\subsection{Single tracks and layer}

To determine working parameters allowing obtaining stable single tracks with constant geometrical shape and required metallurgical properties is an essential part of SLM process (Monroy et al., 2014). The final properties of the tracks for a given powder depend on laser power $(P)$, scanning speed $(V)$ and powder layer thickness $(L)$ (Ciurana et al., 2013). The main challenge of this study was to establish process parameters permitting to obtain stable tracks and, at the same time, preserving the carbide phase from decomposition. For this purpose, experiments were performed with varying scanning velocity and laser power in the range of $100-300 \mathrm{~mm} / \mathrm{s}$ and 50-70 W, respectively. Similar parameter ranges had been successfully applied for SLM of Fe-SiC (Song et al., 2014) and Ti-SiC (Krakhmalev and Yadroitsev, 2014) cermet powders.

The first experiment revealed significant problems in asreceived powder layering because of its weak apparent density and high agglomerating tendency due to a non-spherical particle shape. The minimum layer thickness achieved without visible gaps was of $250 \mu \mathrm{m}$ which is significantly larger than the standard layer thickness for the given equipment and material $(30-50 \mu \mathrm{m})$. The powder was subjected to a heat treatment in an oven at $200{ }^{\circ} \mathrm{C}$ during $2 \mathrm{~h}$. This helped to decrease the level of powder agglomeration, and a homogenous SLM layer with $50 \mu \mathrm{m}$ thickness was achieved. Further experiments were conducted for two powder layer thicknesses: $250 \mu \mathrm{m}$ for the as-received powder, and $50 \mu \mathrm{m}$ for the heat-treated powder.

In the experiments with $250 \mu \mathrm{m}$ layer thickness, no stable continuous tracks with uniform geometry were formed. Under the whole range of tested parameters, the input laser energy was not sufficient to melt the particles of the bottom layer. Thus, metallurgical contact with the substrate was not achieved.

$50 \mu \mathrm{m}$ layer thicknesses permitted to obtain geometrically homogenous tracks. Fig. 3 shows track dimensions versus scanning velocity at $60 \mathrm{~W}$ laser power. $100 \mathrm{~mm} / \mathrm{s}$ scanning velocity was selected as the optimal in the studied range of parameters as it permitted to obtain tracks with constant dimensions. The

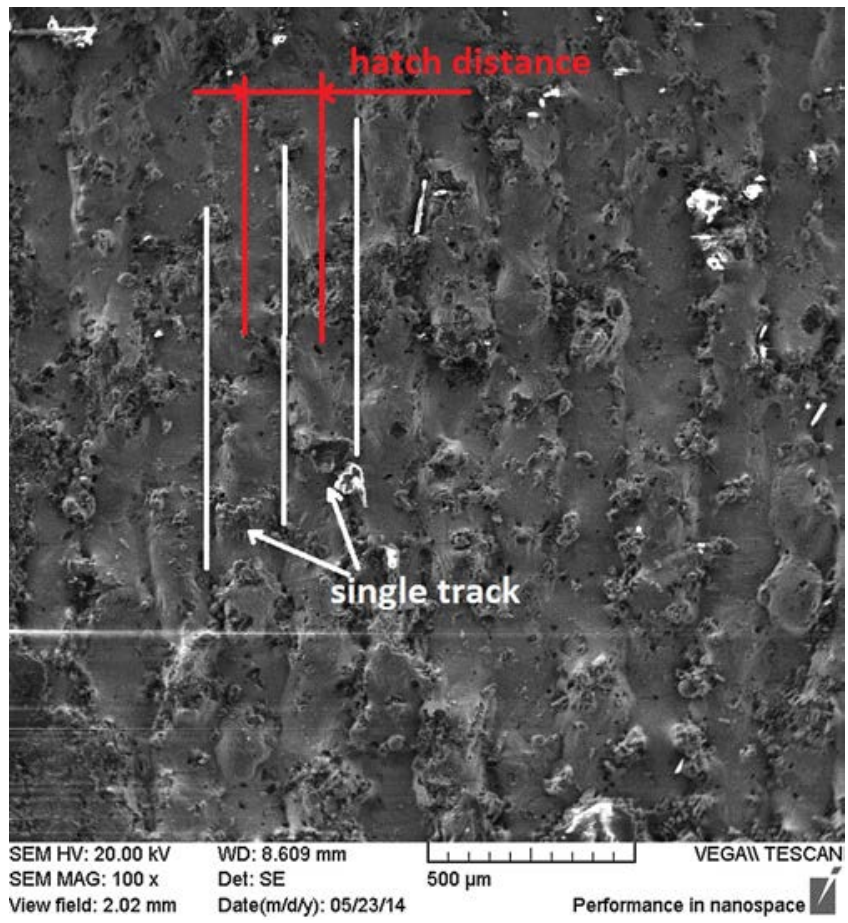

Fig. 4. Top view of the fabricated layer. Process parameters:: laser power $60 \mathrm{~W}$, scanning speed $100 \mathrm{~mm} / \mathrm{s}$, powder layer thickness $50 \mu \mathrm{m}$, hatch distance $120 \mu \mathrm{m}$.

next experimental step was the fabrication of surfaces. Based on the analysis of the single tracks, surfaces were manufactured at the following parameters: laser power $60 \mathrm{~W}$, scanning speed $100 \mathrm{~mm} / \mathrm{s}$, powder layer thickness $50 \mu \mathrm{m}$. $120 \mu \mathrm{m}$ hatch distance (shift between tracks in the plane of the beam scanning) was chosen based on the single track width. Top view of the obtained layer is shown in Fig. 4. One can see that the single tracks composing the layer have a sound metallurgical contact.

\subsection{D samples (cuboids)}

Quality and properties of the whole 3D object depends on those of each fabricated layer. To minimize anisotropy of the cubic sample, the criss-cross strategy previously successfully applied in (Krakhmalev and Yadroitsev, 2014) was used, that is, each next layer was deposited perpendicularly to the previous one. The process parameters were the same as for the fabrication of surfaces. 


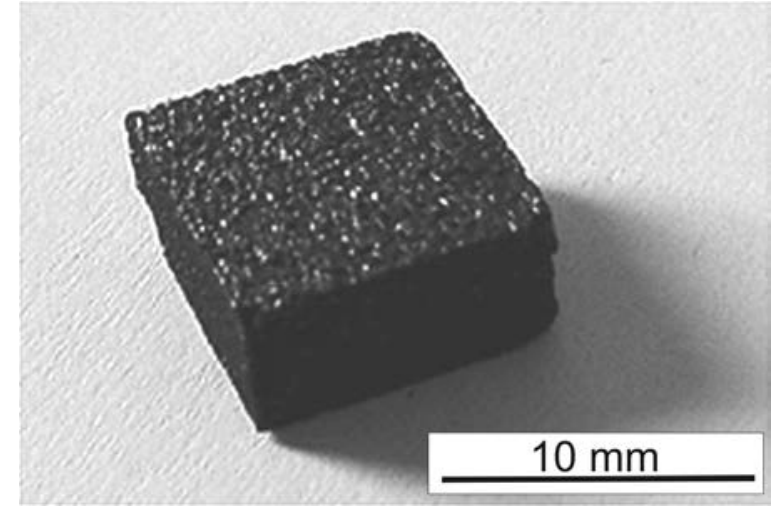

Fig. 5. General view of a $10 \times 10 \times 5 \mathrm{~mm}$ SLM cubic sample.

Table 1

Results of porosity analysis.

\begin{tabular}{lll}
\hline $\begin{array}{l}\text { Theoretical density of } \\
\mathrm{B}_{4} \mathrm{C}-\mathrm{Co}, \mathrm{g} / \mathrm{cm}^{3}\end{array}$ & $\begin{array}{l}\text { Apparent density, } \\
\mathrm{g} / \mathrm{cm}^{3}\end{array}$ & Total porosity, \% \\
\hline 2.95 & 1.86 & 37 \\
\hline
\end{tabular}

Three $10 \times 10 \times 5 \mathrm{~mm}$ cubic samples were fabricated. General view of one of them is presented in Figure 5 .

\subsection{Porosity and microstructure}

Analysis of the cross section images of the obtained cubic samples revealed significant porosity. Pores of two different scales were detected: $10-30 \mu \mathrm{m}$ and $100-200 \mu \mathrm{m}$. The first one was the most probably artificial porosity induced by falling out of hard carbide particles during cutting and grinding of the specimens (Fig. 6). $100-200 \mu \mathrm{m}$ pores were generated under SLM process. Density was measures by Archimedes' method, and the total porosity was found to be very high. The measurement results are presented in Table 1.

It is important to note that the pores are mainly concentrated at the interface region between neighboring tracks and layers. The amount of porosity makes it difficult to distinguish between open and closed porosities. Indeed, the capillarity effects required for Archimedes' method are too weak to allow ethanol used in the measurements to be retained in the open pores of the material.

No large-scale cracking was observed on the samples crosssection but some micro-cracks are visible on SEM images (Fig. 6). Most probably those small-scale cracks were induced by hightemperature gradients during SLM process. On the other hand, sample cutting may also generate local cracks observed in Fig. 6.

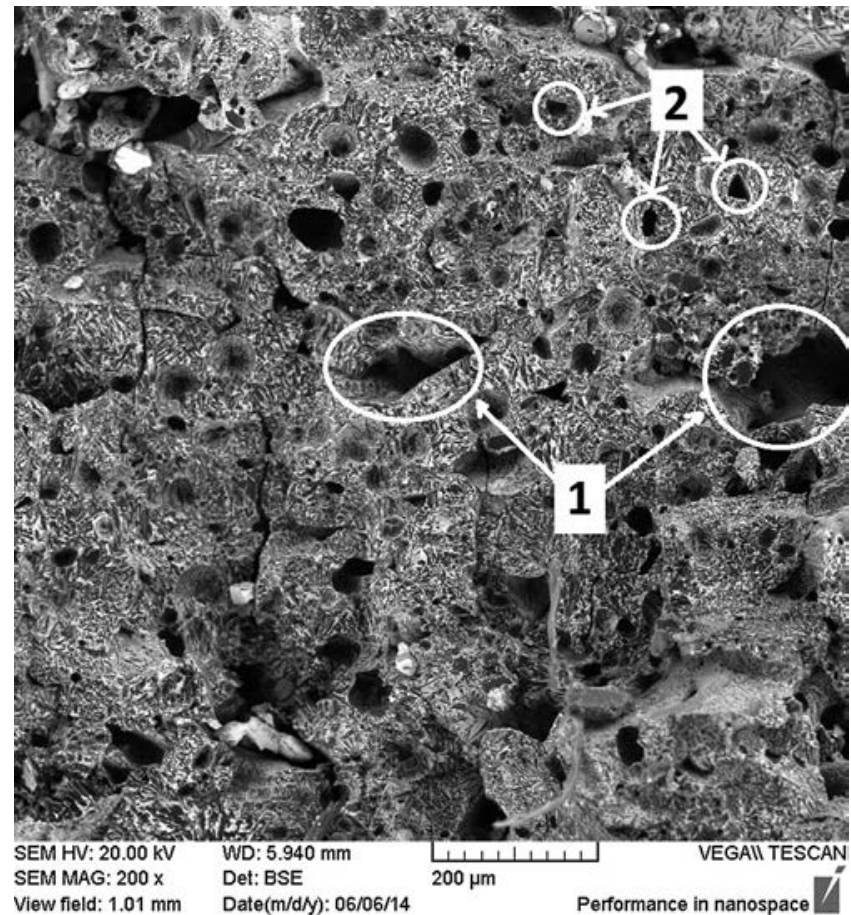

Fig. 6. SEM image of a sample transversal cross-section at low magnification; (1) pores induced during sample fabrication, (2) apparent porosity induced by grinding procedure.

SEM images of the sample surface and cross-section showed that the sample consists mainly of $10-20 \mu \mathrm{m}$ boron carbide grains (that is close to the initial size of the boron carbide particles) surrounded by a cobalt-based matrix (Fig. 7a and b).

Microscopy observations showed that the laser beam melts first the shell material due to a significant difference between the melting temperatures. One can suggest that the molten metal phases of the binder of neighboring particles in the powder bed could interact and create a cobalt based matrix. However, the volume of the metal in the binder is not sufficient to completely fill the voids neither between the particles in single tracks nor in the interfaces between neighboring tracks. It was also observed that high heating and cooling rates of the process lead to the partial melting and resolidification of the boron carbide phase and the formation of new compounds in the cobalt-rich matrix. Additionally to $\mathrm{Co}, \mathrm{Co}_{3} \mathrm{~B}$ and $\mathrm{B}_{4} \mathrm{C}$ phases initially present in the powder before SLM processing the XRD analysis (Fig. 8) also revealed the presence of $\mathrm{Co}_{3} \mathrm{C}$. The formation of these precipitates may generate a significant change

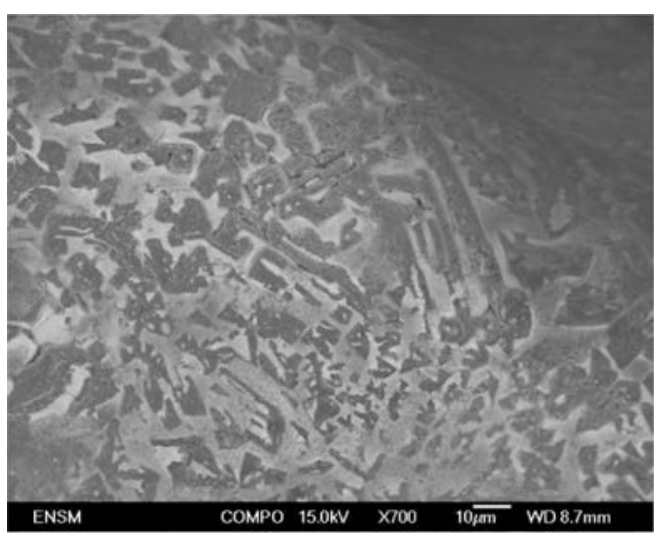

a

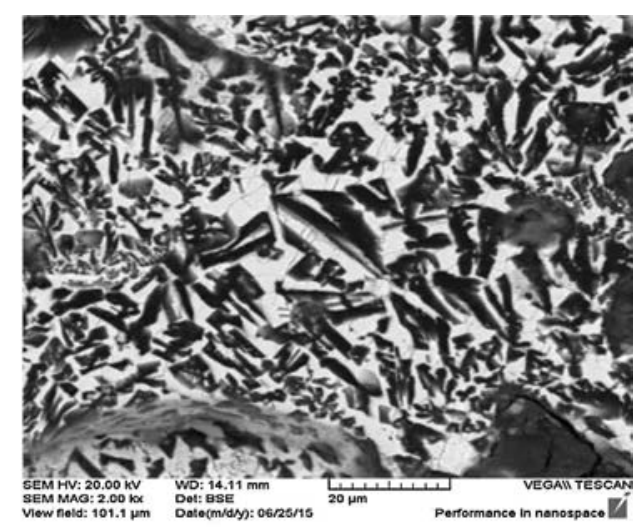

b

Fig. 7. SEM images of the sample: (a) sample surface, (b) sample cross-section. 


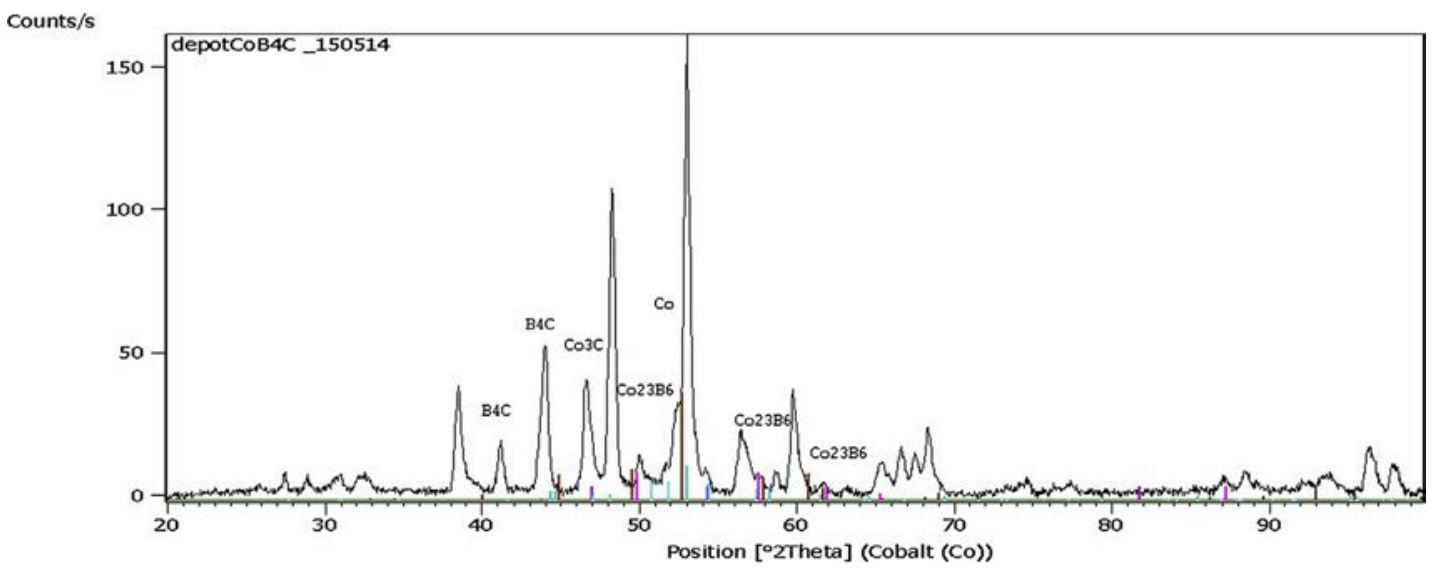

Fig. 8. XRD analysis of the cobalt-based matrix of a sample.

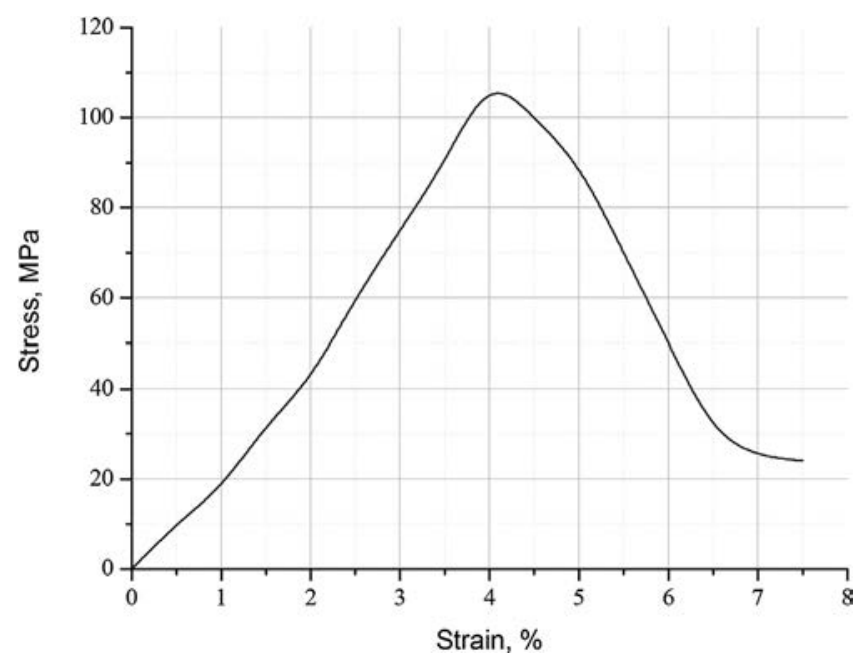

Fig. 9. Stress-strain curve representing results of the compressive strength testing of the sample.

in the behavior of the cobalt-rich binder. Note that XRD analysis of the manufactured object did not allow to clearly observe $\mathrm{Co}_{3} \mathrm{~B}$ initially present in the powder. XRD showed the presence of $\mathrm{CO}_{23} \mathrm{~B}_{6}$ rather than $\mathrm{Co}_{3} \mathrm{~B}$ (Fig. 8).

\subsection{Compressive strength}

The stress-strain curve obtained during sample testing is presented in Fig. 9. As it could be seen from the figure, the maximum stress value was near $110 \mathrm{MPa}$ that corresponded to the formation of visually detectable cracks in the sample volume. Unfortunately, the literature does not report the similar type of compressive strength of a cermet based on $\mathrm{B}_{4} \mathrm{C}-\mathrm{Co}$ obtained by SLM. However, it is known that typical compressive strengths of widely used sintered cermets WC-12\% Co (Ceramics, 2015) as well as pure boron carbide (Mandel et al., 2014) are significantly higher ( 4200 MPa and $2900 \mathrm{MPa}$, respectively).

It is well known that compressive strength of sintered ceramic and cermet parts strongly depends on material properties as well as on the method of sample fabrication (Hausner, 1996). Obviously, total strength of SLM samples should strongly depend on not only the phase composition but also on the strength of the metallurgical contacts between layers and tracks. In case of a cermet sample, strength of the interface contact between the metal and ceramic phases is also an important factor determining the final strength value.

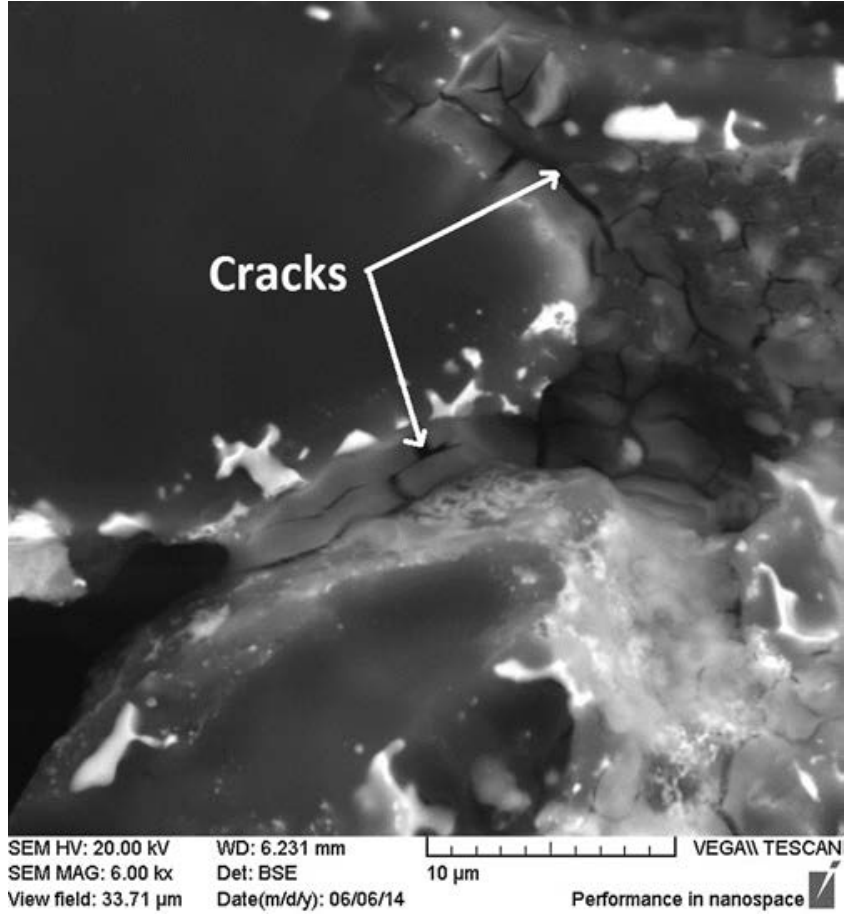

Fig. 10. SEM image of the interface between the metal matrix and boron carbide grains after strength measurements.

As it could be seen from Fig. 10 representing SEM analysis of a destructed sample, fractures mainly propagate in the interface between the metal matrix and the boron carbide particles. Even a partial cracking of boron carbide was not detected. One can conclude that a relatively low value of compressive strength is related to the low strength of the metal matrix with boron carbide particles and a significant overall porosity of the sample.

\subsection{Microhardness}

Microhardness was measured by a Vickers indenter under $300 \mathrm{~g}$ load. Metal matrix as well as ceramic grains was subjected to indentation. The metal matrix yielded about $600 \mathrm{HV}$ hardness. This value is slightly less than that of the cobalt-based particle coating obtained before SLM $(\sim 700 \mathrm{HV})$. Microhardness of the boron carbide grains in the sample was in the range of 2900-3200 HV that is comparable to the hardness of SLM boron carbide parts (Moshtaghioun et al., 2013). 


\section{Conclusion}

- The experiments performed in this study proved the feasibility of building 3D objects of simple geometry by SLM from a cladded powder consisting of ceramic particles surrounded by a metal binder. SLM results for the initial $\mathrm{B}_{4} \mathrm{C}$ powder cladded with a cobalt based binder under the chosen SLM parameters showed that the laser beam had melted the metal, and a metal matrix composite with non-molten ceramic particles inclusions had been formed. Besides, the interaction of $\mathrm{B}_{4} \mathrm{C}$ with the molten metal binder reach in cobalt yielded a new cobalt carbide phase uniformly distributed in the matrix.

- Hardness of the cuboids varies from 600 to 3000 HV depending on the measurement zone.

- The obtained samples have a significant porosity ( $27 \%$ ) mainly distributed in the interlayer region. Porosity may be diminished through the optimization of the ceramic particles granulometry, the increase of the metal binder layer on the ceramic particles, and by a further optimization of the laser scanning parameters.

- Compressive strength of the obtained samples does not exceed $110 \mathrm{MPa}$. This result obviously does not satisfy the targeted application: cutting tools materials. Cracks appear at the interface between the boron carbide particles and the metal matrix, and propagate along the boundaries between the ceramic grains and the metal. High porosity of the samples plays an important role in decreasing the compressive strength mean value. Decreasing porosity may be also a way to enhance mechanical properties of manufactured samples.

\section{References}

Bertrand, P., Bayle, F., Combe, C., Goeuriot, P., Smurov, I., 2007. Ceramic components manufacturing by selective laser sintering. Appl. Surf. Sci. 254 (4), 989-992.

Bucher, S., Iacob, C.,2004.Processes for manufacture of coated metallic particles and composite material, and installation for carrying out these processes, European Patent EP1462539 A1.

Ceramics, 2015, http://www.ceramics.nist.gov/.

Ciurana, J., Hernandez, L., Delgado, J., 2013. Energy density analysis on single tracks formed by selective laser melting with CoCrMo powder material. Int. J. Adv. Manuf. Technol. 68, 1103-1110.
Deckers, J., Vleugels, J., Kruth, J.-P., 2014. Additive manufacturing of ceramics: a review. J. Ceram. Sci. Technol. 05 (04), 245-260.

Feng, C., Guipont, V., Jeandin, M., Amsellem, O., Pauchet, F., Saenger, R., Bucher, S., Iacob, C., 2012. B4C/Ni composite coatings prepared by cold spray of blended or CVD-coated powders. J. Therm. Spray Technol. 21 (3-4), 561-570.

Gu, D., Shen, Y., Dai, P., Yang, M., 2006. Microstructure and property of sub-micron WC-10\% Co particulate reinforced Cu matrix composites prepared by selective laser sintering. Trans. Nonferrous Met. Soc. China 16 (2), 357-362.

Hausner, H.H., 1996. Modern Developments in Powder Metallurgy. Springer, US, pp. $150-157$

Jia, Q., Gu, D., 2014. Selective laser melting additive manufacturing of Inconel 718 superalloy parts: densification, microstructure and properties. J. Alloys Compd. 585, 713-721.

Krakhmalev, P., Yadroitsev, I., 2014. Microstructure and properties of intermetallic composite coatings fabricated by selective laser melting of Ti-SiC powder mixtures. Intermetallics 46, 147-155.

Kruth, J.P., Van der Schueren, B., Bonse, J.E., Morren, B., 1996. Basic powder metallurgical aspects in selective metal powder sintering. Ann. CIRP 45 (1), $183-186$.

Kumar, S., 2009. Manufacturing of WC-Co moulds using SLS machine. J. Mater Process. Technol. 209 (8), 3840-3848.

Li, W.Y., Zhang, C., Liao, H., Li, J., Coddet, C., 2008. Characterizations of cold-sprayed nickel-alumina composite coating with relatively large nickel-coated alumina powder. Surf. Coat. Technol. 202 (19), 4855-4860.

Mandel, C., Krüger, L., Krause, R., Radajewski, M., 2014. The influence of stress state on the compressive strength of WC-Co with different Co contents. Int. J. Refract. Met. Hard Mater. 47, 124-130.

Monroy, K., Delgado, J., Sereno, L., Ciurana, J., Hendrichs, N.J., 2014. Effects of selective laser melting manufacturing process on the properties of CoCrMo single tracks. Met. Mater. Int. 20 (5), 873-884.

Murr, L.E., Martinez, E., Hernandez, J., Collins, S., Amato, K.N., Gaytan, S.M., Shindo, P.W., 2012. Microstructures and properties of 17-4 PH stainless steel fabricated by selective laser melting. J. Mater. Res. Technol. 1 (3), 167-177.

Pupo, Y., Delgado, J., Sereno, L., Ciurana, J., 2013. Scanning space analysis in selective laser melting for CoCrMo powder. Procedia Eng. 63, 370-378.

Shishkovsky, I., Yadroitsev, I., Bertrand, P., Smurov, I., 2007. Alumina-zirconium ceramics synthesis by selective laser sintering/melting. Appl. Surf. Sci. 254 (4), 966-970.

Song, B., Dong, S., Coddet, C., 2014. Rapid in situ fabrication of Fe/SiC bulk nanocomposites by selective laser melting directly from a mixed powder of microsized Fe and SiC. Scr. Mater. 75, 90-93.

Wohlers Report, State of the Industry Annual Worldwide Progress Report, 2007. ISBN 0-9754429-3-7.

Yadroitsev, I., Krakhmalev, P., Yadroitsava, I., 2014. Selective laser melting of Ti6Al4V alloy for biomedical applications: temperature monitoring and microstructural evolution. J. Alloys Compd. 583, 404-409.

Moshtaghioun, B.M., Cumbrera-Hernández, F.L., Gómez-García, D., Bernardi-Martín, S., Domínguez-Rodríguez, A., Monshi, A., Abbasi, M., 2013. Effect of spark plasma sintering parameters on microstructure and room-temperature hardness and toughness of fine-grained boron carbide $\left(B_{4}\right.$ C). J. Eur. Ceram. Soc. 33 (2), 361-369. 